\title{
Examining the pace of change in contraceptive practices in abortion services - a follow-up case study of a quality improvement collaborative
}

\author{
Helena Kilander ${ }^{1,2^{*}}$ (D), Jan Brynhildsen ${ }^{3,4}$, Siw Alehagen ${ }^{2}$ and Johan Thor ${ }^{5}$
}

\begin{abstract}
Background: Among all women who experienced an abortion in Sweden 2017, 45\% had previously underwent at least one abortion. This phenomenon of increasing rates of repeat abortions stimulated efforts to improve contraceptive services through a Quality Improvement Collaborative (QIC) with user involvement. The participating teams had difficulty in coordinating access post-abortion to the most effective contraception, Long-acting reversible contraception (LARC), during the eight-month QIC. This prompted questions about the pace of change in contraceptive services post-abortion. The aim of the study is to evaluate the evolution and impact of QIC changes regarding patient outcomes, system performance and professional development over 12 months after a QIC designed to enhance contraceptive services in the context of abortion.
\end{abstract}

Methods: This follow-up case study involves three multi-professional teams from abortion services at three hospitals in Sweden, which participated in a QIC during 2017. We integrated qualitative data on the evolution of changes and quantitative data regarding the monthly proportion of women initiating LARC, analysed in statistical control charts from before the QIC up until 12 months after its conclusion.

Results: Teams A and B increased the average proportion of women who initiated LARC within 30 days post abortion in the 12 months after the QIC; Team A 16-25\%; Team B 20-34\%. Team C achieved more than 50\% in individual months but not consistently in the Post-QIC period. Elusive during the QIC, they now could offer timely appointments for women to initiate LARC more frequently. Team members reported continued focus on how to create trustful relationships when counseling women. They described improved teamwork, leadership support and impact on organizing appointments for initiating LARC following the QIC.

(Continued on next page)

\footnotetext{
* Correspondence: helena.kilander@ril.se

'Department of Obstetrics and Gynaecology, Eksjö Hospital, Region Jönköping County, Sweden

2Department of Health, Medicine and Caring Sciences, Linköping University, Linköping, Sweden

Full list of author information is available at the end of the article
}

(c) The Author(s). 2020 Open Access This article is licensed under a Creative Commons Attribution 4.0 International License, which permits use, sharing, adaptation, distribution and reproduction in any medium or format, as long as you give appropriate credit to the original author(s) and the source, provide a link to the Creative Commons licence, and indicate if changes were made. The images or other third party material in this article are included in the article's Creative Commons licence, unless indicated otherwise in a credit line to the material. If material is not included in the article's Creative Commons licence and your intended use is not permitted by statutory regulation or exceeds the permitted use, you will need to obtain permission directly from the copyright holder. To view a copy of this licence, visit http://creativecommons.org/licenses/by/4.0/. The Creative Commons Public Domain Dedication waiver (http://creativecommons.org/publicdomain/zero/1.0/) applies to the data made available in this article, unless otherwise stated in a credit line to the data. 


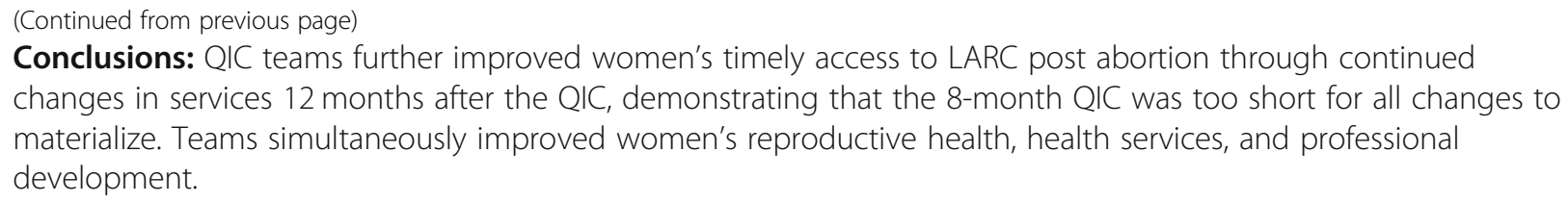

Keywords: Health services accessibility, Long- acting reversible contraception, Contraceptive counselling, System performance, Quality improvement, Professional development and pregnancy termination

\section{Background}

The context of an abortion represents an opportunity to help women to prevent repeat unintended pregnancies (UPs) $[1,2]$. Access to effective contraceptive methods post-abortion, Long-Acting Reversible Contraception (LARC) in particular, is essential for women's sexual and reproductive health $[2,3]$. Moreover, women who use LARC in general report higher rates of satisfaction and 12-month continuation than users of other contraceptive methods [4]. However, the proportion of women who experience repeat abortions in Sweden, as in the UK, is increasing $[5,6]$, despite growing awareness of women's needs for respectful guidance in contraceptive counselling [7-9] and timely access to LARC $[7,10]$.

We recently reported on a Quality Improvement Collaborative (QIC) with user involvement, where three participating teams tested evidence-based changes to improve contraceptive services at the time of abortion [11]. Participating healthcare professionals (HCPs) developed a more person-centred approach to contraceptive counselling in the context of an abortion. None of the teams, however, reached their shared goal of providing $\geq 50 \%$ of women with access to LARC within 30 days post-abortion [11]. The QIC's 8 month duration may have been too short to successfully implement all intended changes, a common challenge in complex health care systems [12].

Batalden and Davidoff define health care quality improvement as the combined efforts of all stakeholders, including patients, that yield changes in several dimensions [12]: "patient outcomes (better health), system performance (better care), and professional development (learning, joy in work) [13]". There is growing support for the benefits of the QIC approach and of user involvement when improving health care services [13-15]. A study of twelve family planning teams in the US indicated that a QIC stimulated the improvement of contraceptive services [15]. The long-term fate and impact of QICs in health care systems, however, especially regarding contraceptive services in abortion care, are still poorly understood.

\section{Methods}

Drawing on Batalden and Davidoff's definition, [13] this study aimed to evaluate the evolution and impact of QIC changes in regard to patient outcomes, system performance, and professional development over 12 months after a QIC designed to enhance contraceptive services in the context of abortion [11]. This report draws on the SQUIRE guidelines (www.squire-statement.org) [16].

\section{Setting and improvement approach}

The QIC brought together teams from abortion services at three departments of obstetrics and gynaecology in south-eastern Sweden; two in mid-sized county-level hospitals (teams A and B) and one in a smaller district hospital (team C). The teams volunteered to join the QIC as part of fulfilling the requirements for health services to undertake quality control and improvement. The QIC drew on the Breakthrough Collaborative model and promoted use of Plan-Do-Study-Act cycles [17]. An interdisciplinary researcher group and an improvement advisor developed, supported, and studied the QIC. It involved four learning sessions (LS) from March to November 2017, with action periods in between when teams tested changes in their practice settings. As a form of user involvement, two women with lived experience of contraceptive counselling at the time of an abortion shared their (de-identified) user perspectives on the teams' proposed changes in order to help the teams to improve the counselling and services [11].

Using a Driver diagram [18], the teams were introduced to four primary drivers for improvement at the time of an abortion, based on previous research evidence $[7,19,20]$ :

- Providing information about contraceptive methods in a better way before, during, and after the first visit.

- Developing a respectful approach to counselling, including on contraception, at the time of an abortion.

- Improving counselling and services to women with communication needs.

- Developing better access to LARC at the time of an abortion.

Developing a respectful approach to counselling included for example, to actively include women in the 
conversation and the decision about subsequent contraception, as well as to use more open questions about contraception, in line with person-centered counselling. These changes were intended to better meet women's individual needs, to facilitate their choice of contraception, and to prevent HCPs from "pushing" skeptical women to choose LARC against their will.

Women with communication needs, defined here as women with language barriers (i.e. who do not speak Swedish), women with mental health problems, women who have experienced repeat abortions and women who decline offers of contraception, seem to have special needs for individually tailored counselling [7].

\section{Study design}

This study is a follow-up of the initial case study [11], combining qualitative and quantitative data collected at six and 12 months after the concluding QIC LS in November 2017. Data concern the fate and impact of the teams' QIC changes.

\section{Data collection}

Qualitative data consisted of field notes from follow-up QIC team meetings at six and 12 months post-QIC, as well as the first author's e-mail correspondence, and notes from telephone conversations with team members.

Quantitative data covered the number of induced abortions and the number of women per month at each site who received LARC within 30 days after the abortion. Data from abortion associated with foetal abnormalities were excluded. The 'time of an abortion' was defined as the time of mifepristone intake (medical abortion) or the day of surgical abortion. Data managers from participating regional health systems extracted, deidentified, and reported data (aggregated per month to protect patient privacy) from administrative information systems regarding the number of abortions and the number of LARC insertions within 30 days post-abortion within the catchment area of each hospital. These data formed the monthly proportion of women who received LARC within 30 days.

\section{Data analysis}

We performed qualitative content analysis of the data according to the framework of Patton [21] from field notes and project documentation. Author HK read through all the data, and coded and arranged the data in categories matching the four primary drivers developed within the QIC [11]. We then analysed the qualitative data deductively based on Batalden and Davidoff's framework [13] regarding patient outcomes, system performance, and professional development. Three other researchers (JT, JB and $\mathrm{SA}$ ) reviewed and refined the analysis individually. The authors discussed and agreed on the analysis through consensus.

As in the initial QIC [11], quantitative data were analysed chronologically using Statistical Process Control charts to identify signs of statistically significant change in performance over time, identified as special cause (non-random) variation [22]. We reviewed the monthly proportion of women who had undergone an abortion and who received LARC within 30 days after the abortion.

We applied three rules to identify statistically significant change:

- A run of six to eight or more points on one side of the center line.

-Two out of three consecutive points appearing beyond $2 \mathrm{SD}$ on the same side of the center line (ie, two-thirds of the way towards the control limits).

- A run of six or eight (some prefer seven) or more points all trending up or down. (Mohammed et al. 2008), [23].

\section{Results}

All three teams participated in two follow-up webinar meetings, at 6 months and 12 months post-QIC. At 6 months, 12 team members and three researchers participated, and at 12 months, five team members and one researcher (HK) took part. Over these 12 months, two of the teams experienced a high turnover of midwives.

The teams reported that during the 12 months after the QIC, they had maintained QIC changes in clinical practice regarding contraceptive counselling and that women's access to LARC had improved. Furthermore, they reported how they had tested additional evidencebased improvement actions, guided by the driver diagram, which they had not tested during the QIC (Table 1).

\section{Improved patient outcomes and system performance regarding access to LARC}

The control charts for teams A and B signalled significant improvements compared to before and during the QIC, in the proportion of women who could initiate LARC within 30 days post-abortion, even if teams A and B did not achieve the $50 \%$ goal post-QIC (Figs. 1 and 2). This improvement was evident as a shift (upwards) in the proportions of women initiating LARC in the time after the QIC (Fig. 2).

Team $C$ achieved the goal of more than $50 \%$ of women receiving LARC within 30 days post-abortion in a couple of separate months post-QIC, with large variations between individual months (Fig. 1) and not a consistent pattern of performing above $50 \%$. In Fig. 1, the observation from August 2018 indicates a special cause as that observation is above the upper control limit. The 
Table 1 Summary of changes and improvements in contraceptive counselling and services 12 months after the QIC

\begin{tabular}{|c|c|c|c|c|c|c|c|}
\hline \multirow[t]{2}{*}{ The four driver categories } & \multirow{2}{*}{$\begin{array}{l}\text { Changes in clinical practice } \\
\text { Subcategories }\end{array}$} & \multicolumn{2}{|l|}{ Team A } & \multicolumn{2}{|l|}{ Team B } & \multicolumn{2}{|l|}{ Team C } \\
\hline & & Maintain & $\begin{array}{l}\text { New } \\
\text { test }\end{array}$ & Maintain & $\begin{array}{l}\text { New } \\
\text { Test }\end{array}$ & Maintain & $\begin{array}{l}\text { New } \\
\text { Test }\end{array}$ \\
\hline \multirow[t]{6}{*}{$\begin{array}{l}\text { Provide information about } \\
\text { contraceptives in a better way } \\
\text { before, at and after the first visit. }\end{array}$} & $\begin{array}{l}\text { - Prepare women better, when women call to make } \\
\text { an appointment for abortion counseling, that the } \\
\text { visit will include contraceptive counselling }\end{array}$ & $x$ & & & $\mathrm{~N}$ & $x$ & \\
\hline & $\begin{array}{l}\text { - Use a visual tool for information about the } \\
\text { effectiveness of different contraceptives }\end{array}$ & $x$ & & $x$ & & $x$ & \\
\hline & $\begin{array}{l}\text {-Use and hand out an information leaflet about side } \\
\text { effects and effectiveness of different contraceptives } \\
\text { when women choose contraceptives }\end{array}$ & & & & & $x$ & \\
\hline & $\begin{array}{l}\text {-Use and hand out an information leaflet about side } \\
\text { effects when women choose contraceptives }\end{array}$ & $x$ & & $x$ & & & \\
\hline & $\begin{array}{l}\text {-Go over both positive and negative side effects } \\
\text { regarding contraceptives }\end{array}$ & $x$ & & $x$ & & $x$ & \\
\hline & $\begin{array}{l}\text {-Show prototypes for different contraceptive } \\
\text { methods }\end{array}$ & & N & & N & $x$ & \\
\hline \multirow{5}{*}{$\begin{array}{l}\text { Develop a respectful approach to } \\
\text { counseling, including on } \\
\text { contraception, at the time of an } \\
\text { abortion }\end{array}$} & -Introduce and use "Do not disturb" signs & & & & & $x$ & \\
\hline & $\begin{array}{l}\text {-Schedule more flexible time for contraceptive } \\
\text { counselling }\end{array}$ & & & & & $x$ & \\
\hline & $\begin{array}{l}\text {-Avoid scheduling less interested physicians when } \\
\text { making abortion counselling appointments }\end{array}$ & & & & & $x$ & \\
\hline & $\begin{array}{l}\text {-Use more open questions in the conversation } \\
\text { about contraception }\end{array}$ & $x$ & & $x$ & & $x$ & \\
\hline & $\begin{array}{l}\text { - Actively include women in the conversation and } \\
\text { decision about contraceptives }\end{array}$ & $x$ & & $x$ & & $x$ & \\
\hline \multirow[t]{5}{*}{$\begin{array}{l}\text { Develop better access to LARC at } \\
\text { the time of an abortion }\end{array}$} & $\begin{array}{l}\text {-Add more appointments for IUD-insertion post } \\
\text { abortion }\end{array}$ & $x$ & & $x$ & & $x$ & \\
\hline & $\begin{array}{l}\text {-Offer/make appointments for IUD-insertion post } \\
\text { abortion directly at the time of abortion counseling }\end{array}$ & $x$ & & $x$ & & $x$ & \\
\hline & $\begin{array}{l}\text {-Offer ("fast track") insertion of IUD- or subdermal } \\
\text { implants within a week post abortion. }\end{array}$ & & $\mathrm{N}$ & $x$ & & $x$ & \\
\hline & $\begin{array}{l}\text {-Increase skills training for midwives in LARC- } \\
\text { insertion post abortion. }\end{array}$ & $x$ & & $x$ & & $x$ & \\
\hline & $\begin{array}{l}\text {-Offer women appointments with midwives instead } \\
\text { of physicians to achieve more timely IUD insertion }\end{array}$ & & & & & $x$ & \\
\hline \multirow[t]{2}{*}{$\begin{array}{l}\text { Improve counselling and services to } \\
\text { women with communication needs }\end{array}$} & $\begin{array}{l}\text {-Schedule women who need an interpreter to } \\
\text { appointments with midwives }\end{array}$ & $x$ & & & & & \\
\hline & $\begin{array}{l}\text {-Refer Arabic-speaking women to written informa- } \\
\text { tion and refer women to websites in different } \\
\text { languages }\end{array}$ & $x$ & & $x$ & & $x$ & \\
\hline
\end{tabular}

"New Test" (N) means that the team tested the change the time after the QIC. "Maintain" means that the team reported at 12 months follow up meeting, that they continue the change in practice. Categories and subcategories represent different steps the qualitative data analysis

underlying cause of this better-than-usual performance is not known.

This improvement in women's timely access to LARC after the QIC (Figs. 1 and 2) was corroborated by HCPs' reports that after the QIC, they had started to offer women appointments to initiate LARC within 10 days post-abortion (Table 1).

All teams reported that they had continued to improve contraceptive and abortion services after the QIC, notwithstanding high midwife turnover in two teams' departments.
Teams A and C reported improved collaboration with the Adolescent Health Services and midwifery clinics in their communities to provide access to LARC post-abortion. These services now also offered and supported fast track for LARC insertion within 10 days post abortion.

The teams also reported experiencing better teamwork and improved support from their department leadership.

"We support each other much more and ask for help in difficult consultations to a greater extent now compared to before the QIC". A midwife in team X. 


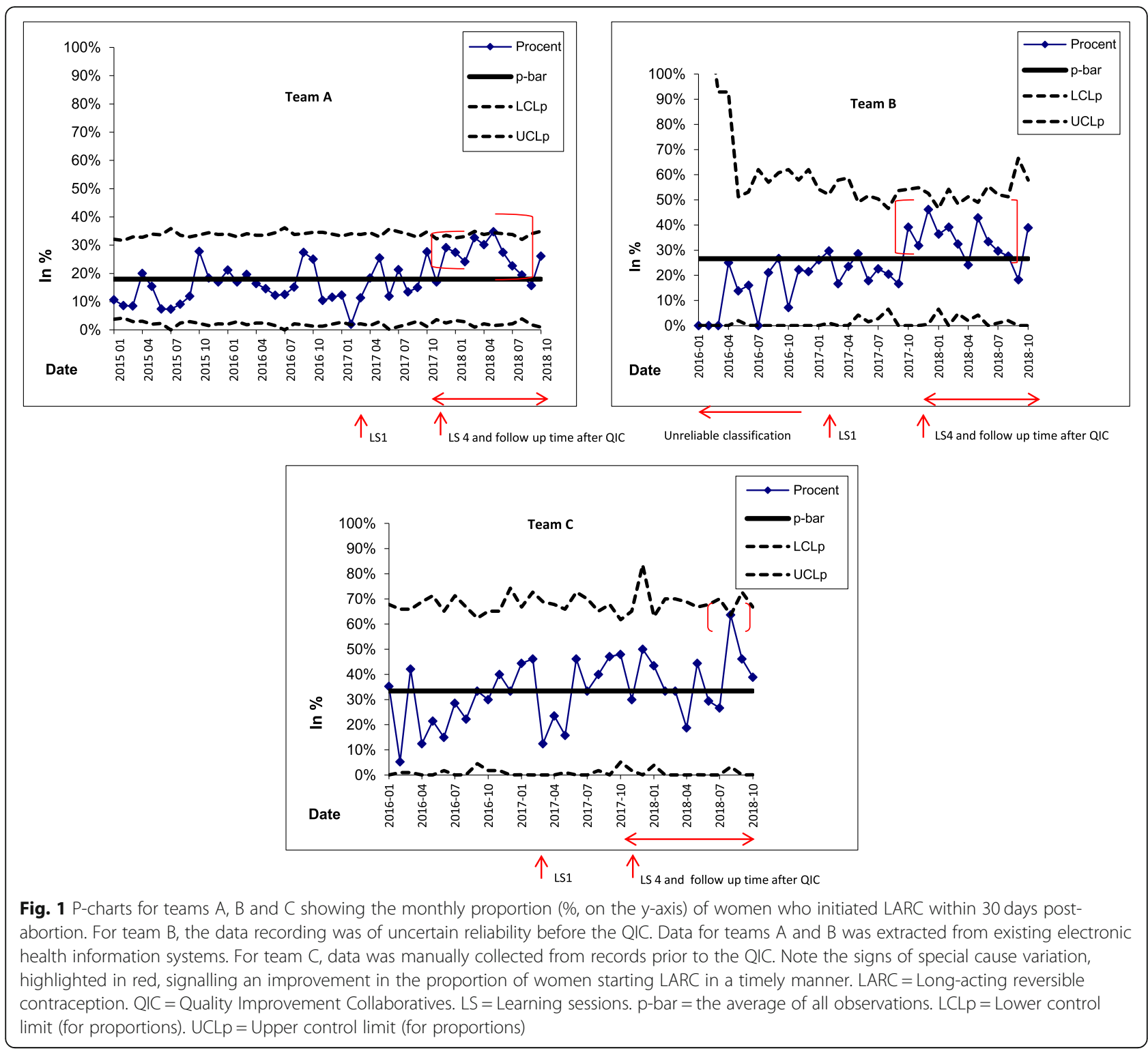

One team described how they could add more appointments for LARC insertion if they needed to; a new capability developed after the QIC.

"Our clinical manager is now interested in the access to LARC post abortion, supports offering women appointments for insertion LARC post abortion and training of staff in LARC insertion. This changed after the QIC."A gynaecologist in team $\mathrm{X}$.

\section{Professional development: experiences of professional} development and improved system performance after the QIC

HCPs reported that they had continued the use of several approaches to contraceptive counselling developed during the QIC (Table 1).
"We experience that women are better prepared for a conversation regarding contraception now." A midwife in team X.

They continued to focus on how to create trustful relationships when counselling women. HCPs also noted their needs for continuous training regarding how to develop trustful relationships and perform respectful counselling. They reported remaining challenges in counselling women who were sceptical towards using hormonal contraception after an unintended pregnancy. Furthermore, they reported that they reflected more on how to avoid pushing sceptical women to choose LARC against their will.

"It is difficult to teach other HCPs how to establish trustful relationships when counselling women who are sceptical of contraceptive methods in the context of abortion." A midwife in team X. 

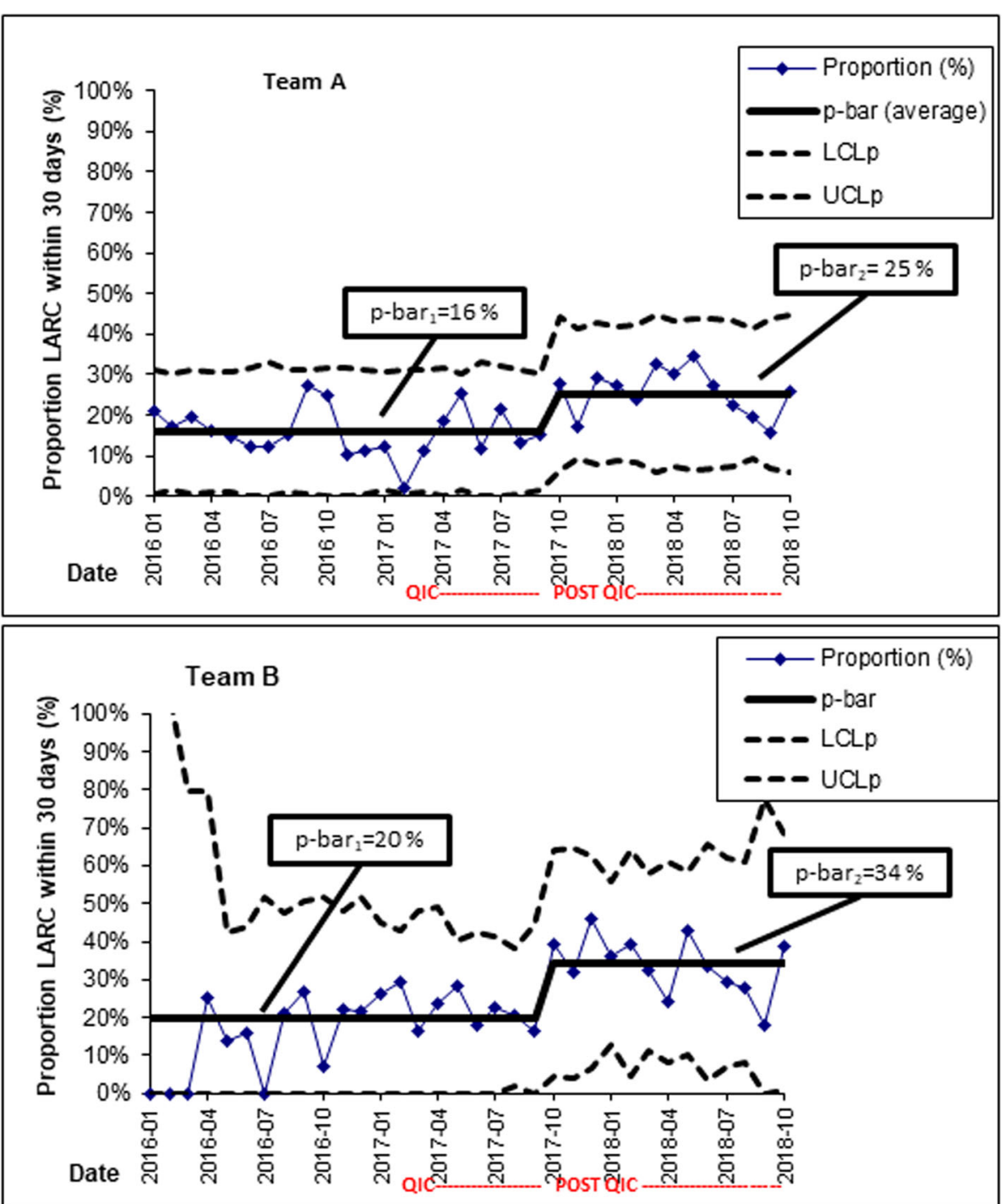

Fig. 2 P-charts for teams A and B showing the monthly proportion (\%, on the $y$-axis) of women who initiated LARC within 30 days post-abortion, with a re-calculated average for the Post-QIC period. This indicates the shifts (i.e. improvement) in the proportions of women who started use of LARC after the conclusion of the QIC, compared to before and during the QIC, for these teams. LARC = Long-acting reversible contraception. $\mathrm{QIC}=$ Quality Improvement Collaboratives. POST-QIC = The follow-up period 12 months after the conclusion of the QIC. LS = Learning sessions. $\mathrm{p}-$ bar $=$ the average of all observations. LCLp = Lower control limit (for proportions). UCLp = Upper control limit (for proportions)

Participating HCPs reported that they continued to practice how to insert LARC after the QIC. This training, which took time (several months) to organize, was fundamental for developing confidence in providing LARC.

They also reported a sense of meaning in providing and improving contraceptive services. They concluded that they were playing an important role now and that this was a new experience since the QIC.

\section{Discussion}

In the 12 months after the QIC, all teams improved access to LARC and thereby increased the proportion of women who initiated LARC within 30 days postabortion. This finding adds encouraging knowledge on how a QIC can enable better patient outcomes, system performance, and professional development, particularly in contraceptive services around the time of abortion. Our results are important, since access to LARC is crucial for improving women's ability to prevent unintended pregnancies $[3,15]$. We know that $45-50 \%$ of women who undergo an abortion return for subsequent abortions $[5,6,24]$, that LARC is associated with a lower risk of unwanted pregnancy $[10,19,25]$, and that both women and HCPs report barriers to LARC in the context of abortion $[1,7,20,26]$. Therefore, improved counselling coupled 
with better access to LARC post-abortion should reduce the risk of unintended pregnancies, and thus promote women's sexual and reproductive health.

Our study demonstrates that change for improvement can take time to materialise [12]. The teams and their departments needed more than the QIC's 8 months duration to see the desired effect of several changes. This included the time to receive support from leadership to make changes in clinical practice $[27,28]$ regarding access to LARC [26]. In our study, support from leadership, including time for training, was fundamental to enable fast track access for LARC insertion within 10 days post abortion. Encouragingly, we found that most of the teams' changes regarding contraceptive services achieved during the QIC were sustained 12 months after the QIC, despite a high midwife turnover in two teams. In that time, teams also introduced additional changes highlighted in the QIC, which they had not managed to introduce during it.

The participating HCPs also reported experiences of professional development due to participating in the QIC. The practical training in LARC methods was pivotal for them to gain confidence in providing LARC, mirroring findings from interviews in 2009 with clinicians in 25 abortion care practices across the USA [26]. Limited knowledge, practical skills training and confidence in providing LARC in abortion care may explain why some HCPs hesitate to recommend LARC or why some women do not receive LARC in a timely fashion post-abortion [26]. Furthermore, like Purcell et al. [9], we found that the HCPs saw a need for training in how to counsel sceptical women, also after the conclusion of the QIC. These findings imply that the HCPs in the abortion care have a continuous need for practical skills training in providing both respectful counselling and LARC.

\section{Methodological considerations and future research}

A strength of this study is its longitudinal character, using quantitative data for the monthly proportion of women initiating LARC in a timely manner over more than 3 years. It is (hypothetically) possible that some of the women received LARC within 30 days post-abortion elsewhere. However, the vast majority of all abortion care services and LARC insertions in the hospitals' catchment area are provided in public health care services.

We were not able to distinguish which change ideas were most, or least, effective when improving access to LARC, a common challenge with these studies. In future research there is a potential to separate varying impact of coinciding changes, e.g. by using Design of Experiments methodology [29].
Furthermore, we were not able to evaluate women's experiences of contraceptive services or the proportion of women who underwent repeat abortions during the study period, as we did in an earlier medical record review study [19] and an interview study [7]. In future studies it would be of value to study the impact of person centred counselling regarding women's satisfaction with contraception and services.

The case study design enabled us to fruitfully combine quantitative and qualitative data. That the teams participated in analysing the quantitative data served as a form of participant validation of the analysis. The multiple forms of data in our study enabled triangulation, strengthening both the study's construct and internal validity [30].

Our findings can guide stakeholders in using a similar QIC approach, with appropriate contextual adaptation [31], to improve contraceptive counselling and services in abortion care. We encourage further studies evaluating QICs, and the changes promoted by the Driver diagram in the present case, in abortion care in a range of contexts. Efforts to better support women who are sceptical and have trouble finding a satisfactory contraceptive method should be prioritised since such women are at particular risk of undesired outcomes.

\section{Conclusions}

A QIC regarding contraceptive counselling and women's access to LARC post-abortion helped clinical teams initiate changes to simultaneously improve patient outcomes, system performance and professional development. Some aspects of improvement, such as offering appointments for LARC initiation in a timely manner, can take longer than an eight-month QIC to fully materialise and yield the intended benefits.

\section{Abbreviations \\ QIC: Quality Improvement Collaborative; LARC: Long Acting Reversible Contraception; UP: Unintended Pregnancy; HCPs: Health Care Professionals}

\section{Acknowledgements}

The authors would like to thank the QIC teams for sharing their experiences. We thank Professor Mattias Elg, Linköping University, for his expert assistance in performing the SPC analyses.

\section{Authors' contributions}

JT, HK, SA and JB designed the study. JT, HK and SA participated in data analysis with assistance from Professor Elg. JT, HK, SA and JB participated in manuscript writing. All authors read and approved the final version.

\section{Funding}

This study was funded by grants from Futurum - the Academy for Healthcare, in the Jönköping County Region, and the Medical Research Council of Southeast Sweden (FORSS). Open Access funding provided by Linköping University Library.

The funders had no role in study design, data collections and analysis, decision to publish or preparation of the manuscript. 


\section{Availability of data and materials}

The dataset generated and/or analysed during the current study are not publicly available due to restrictions from the Ethics Review Board, but can be made available to qualified researchers upon request, after approval from the Ethics board. HK should be contacted if someone wants to request the data.

\section{Ethics approval and consent to participate}

This study was conducted in keeping with principles for research ethics, including informed verbal consent by all participating team members and protection of the integrity and dignity of individuals [32]. It includes no individual data from identifiable patients, only aggregate data from the health systems. The Ethical Review Committee in Linköping approved informed verbal consent by all participating team members. The study was approved by the Regional Ethical Review Committee in Linköping, Sweden The reference number is 2016/486-31; date of approval 22 February 2017.

\section{Consent for publication}

Not applicable.

\section{Competing interests}

Two of the co-authors have been reimbursed by Merck Sharpe \& Dohme Bayer AB Sweden (JB, HK) and Actavis (JB) for running educational programmes and giving lectures. The other co-authors have stated that they have no conflicts of interest in connection with this manuscript.

\section{Author details}

'Department of Obstetrics and Gynaecology, Eksjö Hospital, Region Jönköping County, Sweden. ${ }^{2}$ Department of Health, Medicine and Caring Sciences, Linköping University, Linköping, Sweden. ${ }^{3}$ Department of Obstetrics and Gynaecology and Department of Biomedical and Clinical Sciences, Linköping University, Linköping, Sweden. ${ }^{4}$ Department of Obstetrics and Gynecology, Faculty of Medicine and Health, Örebro University, Linköping, Sweden. ${ }^{5}$ Jönköping Academy for Improvement of Health and Welfare, School of Health and Welfare, Jönköping University, Jönköping, Sweden

\section{Received: 14 April 2020 Accepted: 5 October 2020}

\section{Published online: 16 October 2020}

\section{References}

1. Benson J, Andersen K, Brahmi D, Healy J, Mark A, Ajode A, et al. What contraception do women use after abortion? An analysis of 319,385 cases from eight countries. Glob Public Health. 2016;18:1-16.

2. World Health Organization. Sexual health and its linkages to reproductive health: an operational approach 2017 [Available from: http://apps.who.int/iris/bitstream/ handle/10665/258738/9789241512886-eng.pdf;jsessionid=COBA7ADA58A02724 BE3E382F8F740D30? sequence=1. Accessed 27 March 2020

3. Gavin LE, Ahrens KA, Dehlendorf C, Frederiksen BN, Decker E, Moskosky S. Future directions in performance measures for contraceptive care: a proposed framework. Contraception. 2017;96(3):138-44.

4. Peipert JF, Zhao Q, Allsworth JE, Petrosky E, Madden T, Eisenberg D, et al. Continuation and satisfaction of reversible contraception. Obstet Gynecol. 2011;117(5):1105-13.

5. Socialstyrelsen. Abortstatistik 2018 [Available from: https://www. socialstyrelsen.se/statistik-och-data/statistik/statistikamnen/aborter/. Accessed 27 March 2020.

6. United Kingdom Government. Report on abortion statistics in England and Wales for 20182018 [Available from: https://assets.publishing.service.gov.uk/ government/uploads/system/uploads/attachment_data/file/808556/Abortion_ Statistics_England_and_Wales_2018_1_.pdf. Accessed 27 Mar 2020.

7. Kilander $\mathrm{H}$, Bertero C, Thor J, Brynhildsen J, Alehagen S. Women's experiences of contraceptive counselling in the context of an abortion - an interview study. Sexual Reprod Healthc. 2018;17:103-7.

8. Dehlendorf C, Henderson JT, Vittinghoff E, Grumbach K, Levy K, Schmittdiel J, et al. Association of the quality of interpersonal care during family planning counseling with contraceptive use. Am J Obstet Gynecol. 2016;215(1):1-9.

9. Purcell C, Cameron S, Lawton J, Glasier A, Harden J. Contraceptive care at the time of medical abortion: experiences of women and health professionals in a hospital or community sexual and reproductive health context. Contraception. 2016;93(2):170-7.
10. Cameron ST, Glasier A, Chen ZE, Johnstone A, Dunlop C, Heller R. Effect of contraception provided at termination of pregnancy and incidence of subsequent termination of pregnancy. BJOG. 2012;119(9):1074-80.

11. Kilander H, Brynhildsen J, Alehagen S, Fagerkrantz A, Thor J. Collaboratively seeking to improve contraceptive counselling at the time of an abortion: a case study of quality improvement efforts in Sweden. BMJ Sex Reprod Health. 2019:45(3):190-9.

12. Grol R, Grimshaw J. From best evidence to best practice: effective implementation of change in patients' care. Lancet. 2003;362(9391):1225-30.

13. Batalden PB, Davidoff F. What is "quality improvement" and how can it transform healthcare? Qual Saf Health Care. 2007;16(1):2-3.

14. Batalden M, Batalden P, Margolis P, Seid M, Armstrong G, Opipari-Arrigan L, et al. Coproduction of healthcare service. BMJ quality \& safety. 2016;25:509-17.

15. Loyola Briceno AC, Kawatu J, Saul K, DeAngelis K, Frederiksen B, Moskosky $\mathrm{SB}$, et al. From theory to application: using performance measures for contraceptive care in the title $X$ family planning program. Contraception. 2017;96(3):166-74

16. Ogrinc G, Davies L, Goodman D, Batalden P, Davidoff F, Stevens D. SQUIRE 2.0 (standards for QUality improvement reporting excellence): revised publication guidelines from a detailed consensus process. BMJ quality \& safety. 2016;25(12):986-92.

17. Langley GJ, Moen R, Nolan KM, Nolan TW, Norman CL, Provost LP. The improvement guide : a practical approach to enhancing organizational performance (2nd ed.). San Francisco: Jossey-Bass; 2009.

18. Bennett BPL, What's YOUR. Theory? Qual Prog. 2015;48(7):36-43.

19. Kilander H, Alehagen S, Svedlund L, Westlund K, Thor J, Brynhildsen J. Likelihood of repeat abortion in a Swedish cohort according to the choice of post-abortion contraception: a longitudinal study. Acta Obstet Gynecol Scand. 2016;95(5):565-71.

20. Kilander H, Salomonsson B, Thor J, Brynhildsen J, Alehagen S. Contraceptive counselling of women seeking abortion - a qualitative interview study of health professionals' experiences. Eur J Contracept Reprod Health Care. 2017;22(1):3-10.

21. Patton M. Qualitative research \& evaluation methods. London: SAGE; 2002.

22. Provost LP, Murray SK. The health care data guide:learning from data for improvement. 1st ed ed. San Fransisco: Jossey-Bass; 2011.

23. Mohammed MA, Worthington P, Woodall WH. Plotting basic control charts: tutorial notes for healthcare practitioners. Qual Safety Health Care. 2008;17: 137-45.

24. Toprani A, Cadwell BL, Li W, Sackoff J, Greene C, Begier E. Repeat abortions in New York City, 2010. Journal Urban Health. 2015;92(3):593-603.

25. Winner B, Peipert JF, Zhao Q, Buckel C, Madden T, Allsworth JE, et al. Effectiveness of long-acting reversible contraception. N Engl J Med. 2012; 366(21):1998-2007.

26. Morse J, Freedman L, Speidel JJ, Thompson KM, Stratton L, Harper CC. Postabortion contraception: qualitative interviews on counseling and provision of long-acting reversible contraceptive methods. Perspect Sex Reprod Health. 2012:44(2):100-6.

27. Sannisto T, Saaristo V, Stahl T, Mattila K, Kosunen E. Quality of the contraceptive service structure: a pilot study in Finnish health Centre organisations. Eur J Contracept Reprod Health Care. 2010;15(4):243-54.

28. Tistad M, Palmcrantz S, Wallin L, Ehrenberg A, Olsson CB, Tomson G, et al. Developing leadership in managers to facilitate the implementation of National Guideline Recommendations: a process evaluation of feasibility and usefulness. Int J Health Policy Manag. 2016;5(8):477-86.

29. Olsson J, Terris D, Elg M, Lundberg J, Lindblad S. The one-person randomized controlled trial. Qual Manag Health Care. 2005;14(4):206-16.

30. Yin R. Case study research: design and methods. 4th ed. Los Angeles: Sage publications; 2009

31. Harvey G, Jas P, Walshe K. Analysing organisational context: case studies on the contribution of absorptive capacity theory to understanding interorganisational variation in performance improvement. BMJ Qual Saf. 2015; 24(1):48-55.

32. The Swedish Research Council and CODEX at Uppsala University. CODEXOverview of rules and guidelines for research [In Swedish: samlingen av regler och riktlinjer för forskning]. 2019 [Available from: http://www.codex.vr. se/omcodex.shtml. Accessed 27 March 2020.

\section{Publisher's Note}

Springer Nature remains neutral with regard to jurisdictional claims in published maps and institutional affiliations. 